This is a post-print version of the following article: Vargas-Urpi, Mireia (2016). Problems and strategies in public service interpreting as perceived by a sample of Chinese-Catalan/Spanish interpreters. Perspectives, 24 (4), 666-678. Doi: 10.1080/0907676X.2015.1069861

\title{
Problems and strategies in public service interpreting as perceived by a sample of Chinese-Catalan/Spanish interpreters
}

\author{
Mireia Vargas-Urpi ${ }^{*}$ \\ Universitat Pompeu Fabra \\ Barcelona, Spain \\ mireia.vargas@upf.edu
}

\begin{abstract}
Problems and strategies have been widely discussed in Translation and Interpreting Studies, but they have received scarce attention in the field of Public Service Interpreting (PSI). On the basis of interviews with twenty public service interpreters working in the Chinese-Catalan/Spanish combination, this article analyses their answers in relation to the problems and difficulties they usually encounter, which are classified into two categories: word level and discourse level. Different ideas on curriculum design and training approaches are suggested and discussed on the basis of this analysis, while also considering that most interpreters had not received formal training in PSI at the moment of the interviews.
\end{abstract}

Keywords: public service interpreting (PSI), community interpreting, dialogue interpreting, PSI training, PSI problems and strategies, qualitative interviews

\footnotetext{
* Department of Translation and Language Sciences, Universitat Pompeu Fabra. Roc Boronat, 138, 08018 Barcelona (Spain). Email: mireia.vargas@upf.edu
} 


\section{Introduction}

Public service interpreting (PSI) has been a growing field both in terms of research as well as training. Research has shed light on many different aspects that have been crucial to develop training curricula: from the importance of ethical codes and deontology, to the most commonly used interpreting modes and techniques in public services. Training is regarded as a key element in the professionalisation of PSI practice, and this has also been reflected in research.

Surveys have been frequently used as a research method into PSI (Hale, 2007, p. 219). Surveys have followed a quantitative approach (by means of questionnaires), a qualitative approach (by means of interviews or focus groups) or a mixed approach, combining them both. Most research basing on surveys seeks to obtain information from the participants involved in PSI interactions (i.e., interpreters, public service providers and/or users) in order to describe different aspects of PSI practice according to informants' responses.

The primary aim of this article is to discuss PSI interpreters' challenges and coping strategies in their interpreting work. It is based on a qualitative research that has used in-depth interviews to obtain information from twenty public service interpreters working with the Chinese community in Catalonia. This information will be used to shed light on a topic problems and strategies in PSI - that has been under-explored to date, especially if compared to written translation or to conference interpreting.

\section{Problems and strategies}

Problems and strategies have been widely discussed in Translation Studies (Molina \& Hurtado Albir, 2002; Gil-Bardají, 2009). Concerning the definition of 'problem’, Nord (1991, p. 151) defines translation problem as 'an objective problem which every translator has to solve during a particular translation task.' Later on, Nord suggests the following classification for translation problems: pragmatic translation problems, convention-related translation problems, linguistic translation problems and text specific problems (cf. 2005, p. 174-176). While Nord's classification is clearly text-oriented, some of the problems she mentions (e.g. convention-related translation problems) may also be found in PSI.

As for 'strategy', Hönig and Kussmaul (1982) and Hurtado (2001) suggest the following definition: a process that leads to an optimal solution for a translation problem. ${ }^{1}$ Looking up the meaning of a word is considered a strategy for a translation problem. According to

\footnotetext{
1 For a critical review of the terminology used by scholars to study the translation process (e.g. 'strategies', ‘techninques', 'processes', 'methods', etc.), see Gil-Bardají (2009).
} 
Hurtado (2001, p. 277), problems may be linguistic, extralinguistic, instrumental or pragmatic.

In the field of Interpreting Studies, under the umbrella of the Effort Model, Gile (1995) coined the term 'specific problem triggers', such as numbers, names, enumerations, idioms etc. in simultaneous interpreting, i.e. problems that may result in interpreting errors ('failure sequences') and may need specific 'coping tactics'.

Kalina (2000) uses Færch \& Kasper’s (1984, p. 47) definition of strategy: 'potentially conscious plans for solving [...] a problem in reaching a [...] communicative goal', which again stresses the importance of the problem-strategy pairing. Kalina studies strategies as part of the interpreting competence and describes the following strategies:

Comprehension strategies include segmentation of input, anticipation, inferencing, accessing previously stored knowledge, building relations between stored and new information, in short, mental modelling. Text production strategies comprise restructuring, paraphrasing, condensing or expanding information, and the use of prosodic or non-verbal features. Global strategies are of a more general and comprehensive nature; they involve memorizing the input, adapting one's mental model, monitoring one's own output for deficiencies but also that of the text producer for coherence and repairing errors (2000, p. 7).

Other authors have studied the problem-strategy pairing in simultaneous interpreting (cf. Sunnari, 1995; Gran, 1998; Abuín, 2007; Arumí, 2012, among others), but less have focused on this specific topic in the field of PSI, apart from Vargas-Urpi and Arumí (2014) who explicitly talk about problems and strategies in the analysis of an interpreter-mediated interaction. Other authors mention the strategic performance of interpreters, especially in relation to role issues: e.g., Pöllabauer (2004, p. 163) describes 'face-saving strategies' and Merlini and Favaron (2003) mention 'power management strategies', but do not focus on the pairing.

Concerning the methods used to study strategies in translation and interpreting, researchers have mainly relied on verbal reports. On the one hand, think-aloud protocols have been used to study the translation process (cf. Lörscher, 1991; Kiraly, 1995). On the other hand, retrospective interviews have been used in interpreting (Abuín, 2004; Napier, 2004) to ask interpreters about the problems perceived in given tasks and the strategies relied on to solve them. 


\section{The study}

A better understanding of the nature of the problem-strategy pairing in actual interpreter performance can help in the design of training programmes and activities so that they respond more closely to the difficulties trainees will encounter in real assignments. Therefore, the aim of this article is to take stock of the awareness among public service interpreters concerning the problems and difficulties they have to face in daily PSI practice. It also assesses the strategies used by interpreters in the study sample and discusses how these strategies could benefit from specific training in PSI, considering that most interpreters of the sample had not received this kind of training.

With this aim in mind, a qualitative method was chosen. Data collection consisted of interviews with twenty public service interpreters working with the Chinese community in Catalonia. As part of a larger research project, interviews covered a wide range of topics concerning PSI and intercultural communication with the Chinese. For instance, some questions referred to interpreters' background and experience, or to their views of intercultural communication between Chinese users and Catalan providers (cf. Vargas-Urpi, 2014). However, this paper will only focus on information related to problems and strategies. Despite not being retrospective interviews -i.e. related to a specific task or assignment-, these verbal reports can be used as a source of information on what is perceived as problems by the interpreters of the sample.

The interviews were conducted between March and December 2010 and they were informal and semi-structured, i.e., even though there was a list of questions and topics to be covered during the interviews, it was not a fixed guide, and it could be adapted to interviewees' answers. New questions could be added and the order of questions could be changed if, as interviewers, we felt it could help us obtain additional or relevant information.

Interviews were recorded and transcribed verbatim. Qualitative content analysis (Mayring, 2000) was used to assign codes and develop a formative analysis (Hertog et al., 2006) by means of Atlas.ti, a qualitative data analysis program. Some codes were related to our research questions or objectives and foreseen in the interview guides, but others were totally unexpected from the point of view of our research approach and deemed important to describe the object of study. These codes reflect the categories that will be discussed later on, namely, word-level and discours-level, and were used to classify the informants' responses.

The main limitation of the present study is only having collected information from Chinese-Catalan/Spanish interpreters, which is due to the broader scope of the research this 
article is taken from. However, the kind of information collected in relation to problems, strategies and needs can easily be extrapolated to PSI in other language and culture pairs, and the specific examples highlight the kinds of problems that crop up when interpreting between distant languages and cultures.

\section{The sample of informants}

All those interviewed were interpreters or intercultural mediators ${ }^{2}$ working in Catalan public services at the moment of the interview: fifteen were women, while five were men. This breakdown is frequent in the field of PSI (Arumí et al., 2011), which has been described as a feminised profession.

Concerning their origin, twelve interviewees were Chinese, seven were European and one was from Latin America. Nineteen of them had university degrees: four in Translation and Interpreting ${ }^{3}$ and six in Sinology or East Asian Studies; while the other informants came from a range of university backgrounds (Medicine, Law or Politics, among others). Eight of them had received informal training in Intercultural Mediation and only three informants had received specific PSI training in ad hoc short courses (from 12 to 20 hours).

The informants' experience as public service interpreters or intercultural mediators was also varied: five of them had been working in this field for less than one year, while four of them had been interpreters or mediators for five to ten years. In terms of working profile, seven worked full-time, five had part-time contracts and eight were freelance, working occasionally.

Summing up, the sample of interpreters interviewed is heterogeneous both in terms of education and working experiencie. Furthermore, none of them had received formal training in PSI, a fact that must be considered when approching the information provided in their interviews.

\section{Problems and strategies}

This section focuses on the problems recalled by the interpreters who participated in our interviews and on the kinds of strategies they relied on to overcome them. These problems have been classified into two categories: word-level and discourse-level. Word-level problems refer to the microtextual units that make up participants' interventions in an interpreter-

\footnotetext{
2 Despite describing themselves as 'intercultural mediators' and assuming other functions than interpreting, these interviews only focused on their function as interpreters.

${ }^{3}$ In Spain, Translation and Interpreting degrees have not included PSI contents until relatively recently, after the creation of the European Higher Education Area, implemented during the course 2009-10.
} 
mediated interaction, while problems concerning discourse generally emerge when the way the information is presented differs between the provider and the user. Apart from these, some general linguistic problems are also mentioned in the interviews. They mainly refer to lack of knowledge of specific linguistic varieties used by Chinese users. It must be noted that Chinese linguistic varieties (geolects and dialects) are often mutually unintelligible, therefore if the user and the interpreter cannot share a lingua franca (for instance, Standard Chinese), effective communication may be impossible. However, this kind of problem is scarce in our corpus of interviews.

\subsection{Word-level}

Not understanding certain words or terms is one of the most frequent problems among the informants of the sample. Nonetheless, it must be noted that six informants state they did not experience any problems with words or terminology. Familiarity with the topic and experience in the field where they work are two of the arguments that support their claim. For instance, informant $19,{ }^{4}$ who studies Law and works as a court interpreter, feels confident with the terminology used in this field. Informant 9 agrees on the fact that experience and familiarity reduce semantic problems, even though he also admits always taking a dictionary to feel more confident, but he 'seldom uses it'.

Despite these examples, thirteen informants admit to have problems with terminology. For instance, informant 12 once left a telephone interpreting assignment unfinished because he felt he lacked preparation and the necessary terminology:

Extract 1. [Informant 12, Chinese healthcare, education and social services interpreter]

[The provider] started saying vaccination names and I was stunned, I told him: 'I can't do this job; I can’t continue because this vocabulary is very technical, very specific, and if you're not warned in advance, it's impossible'. ${ }^{5}$

In this specific case, perhaps the fact that it was a telephone interpretation made the interpreter feel under more pressure. In other examples, face-to-face interpreting helps informants find different strategies to solve semantic problems. Eight informants explain they ask for the meaning of the unknown word to providers or users. Interpreters then normally describe the term according to the explanation provided, omitting the term in the rendition.

\footnotetext{
${ }_{5}^{4}$ Numbers are used to preserve informant anonymity.

${ }^{5}$ Interviews were conducted in Catalan or Spanish. The excerpts presented in this article have been translated by the author.
} 
Informant 11 not only describes the term, but also adapts this explanation to the register of the user:

Extract 2. [Informant 11, Chinese healthcare interpreter]

I ask what that means. (...) And the doctor explains what it is. And in Chinese I don't know how to say that using medical terms, but it's not necessary, because, to tell you the truth, Chinese don't know them either. And then, I explain to them what it is, using very plain language, and relying on visual input, and then they know. If necessary, I also ask the doctor to draw a picture to help them understand.

As may be noted, informant 11 actively modifies the message to adapt it to what she expects users will understand better. Informant 13 admits a similar stance and justifies not transmitting the terminology in Chinese because users would not understand it, 'because they have not received higher education'. As for informant 18, a court interpreter, he omits the most ritualised parts of the discourse (for instance, when lawyers use Latin expressions), because he feels they are not relevant to the interaction. These three examples clearly reflect how interpreters intervene in the transmission of messages and, moreover, how they justify these shifts as the best option. Despite responding to problems which are semantic in nature related to the meaning of specific words-, this kind of solution also affects the pragmatic content of the rendition, as it changes the style from specialised to more general.

On the contrary, three informants use the bilingual dictionary when they do not understand a specialised term and try to translate it with the Chinese equivalent, even though they sometimes also ask the provider. According to informant 9, if users can understand the equivalent suggested by the dictionary, he does not ask the provider for any additional information.

Apart from dictionaries, another resource mentioned by informants is Internet. More specifically, two healthcare interpreters explain that Internet is easily accessed at the hospital and they use it to check terminology. Informant 1 mainly searches Google, but she also uses a specific program to support multilingual communication in healthcare encounters. ${ }^{6}$ Informant 13 uses Internet to solve semantic problems and she mentions Chinese-Spanish translation forums, as well as Wikipedia. However, she searches words and terms once the interpreted session has ended, when she gets home. She thinks this is a way to improve, as these are 'things she must know'.

\footnotetext{
${ }^{6}$ She refers to Universal Doctor Speaker. URL: http://www.universaldoctor.com/ (accessed $12^{\text {th }}$ August 2014).
} 
Finally, some cultural references also pose problems which can be located at the wordlevel, as the interpreting difficulty consists of the non-existence of an equivalent in the target language (cultural translation problems according to Nord's classification). In the corpus of interviews, a common example is 'county council' (consell comarcal), which in Catalan refers to an administrative unit that gathers the different city councils in a county. This administrative category does not have a direct equivalent in Chinese and results in interpreters finding different ways to transmit this idea. Some interpreters worked in the interpreting service of a county council, which is why they coincide on talking about this specific example. Three informants (INF12, INF13, INF14) introduce themselves as interpreters at the city council, changing the referent but using a similar reality. Informant 12 explains that talking about a 'county council' would be difficult for the users to understand, which is the reason why she uses an easier referent (city council). To avoid referring to county councils, informant 15 introduces herself as the 'interpreter from education services', and informant 16 as a 'social services worker'; both descriptions used in an attempt to provide an easier referent.

However, when talking about places where users will need to go, eight informants stress that it is important that users recognise and know how to pronounce these referents in the source language (Catalan or Spanish). Therefore interpreters resort to amplifications: they mention the original term and add a description or an equivalent in Chinese. Informant 11 even notes these names down on a paper to help users learn basic words, while informant 1 adapts the 'extra' information to what she thinks the users may need -for instance, she adds information about buses or how to find specific places. Despite being more informative, this role is also more paternalistic, as she assumes users will not understand the information provided otherwise.

\subsection{Discourse level}

Problems at the discourse level may be motivated by differences in the register or by the divergences between discursive patterns in each language. This kind of problem are more difficult to detect from the interpreter's point of view, because they do not involve difficulties in understanding a message or in the translation of specific items, but in the way implicit content is transmitted.

Informant 3, for instance, talks about knowing how to express certain pieces of information. She recalls the following situation: 
Extract 3. [Informant 3, Catalan education and social services interpreter]

(...) You need to know how to approach the topic. (...) It was my first time having to say to a Chinese person that he needed to go to a psychologist, to check if was suffering from depression or not... The teachers in the school also hesitated on whether this kid had some kind of mental retardation, because he was not learning like the others... And well, I had to rely on facial expression and so on. If I cannot fully rely on verbal information, I usually resort to non-verbal communication.

Knowing how to render the information is very important to effectively transfer the message and avoid misunderstanding, especially in such sensitive issues. In this specific example, there was also the influence of cultural values in the social conception of psychologists, as in China they are often related to treating serious mental diseases.

Informant 5 also seems to have a clear idea of the difficulties of transmitting the covert information. When talking about PSI for the Chinese, she explains that the most difficult thing is transmitting how the speaker really feels:

Extract 4. [Informant 5, Catalan education and social services interpreter]

Sometimes, when you hear a Chinese person talking in Chinese you know if he or she is being rude, or if he or she is trying to hurt the other person, you know? Transmitting this kind of information is often the most difficult.

Certainly, reflecting implicit content, such as rhetorical resources (irony, sarcasm, metaphors) or feelings and emotions is essential to truly reflect the speaker's intentions. Informant 5 intervenes in the conversation using her own voice to explain these hints that may slightly change what has just been said.

Problems concerning the pragmatic value of certain kinds of discourse are often found in court interpreting. Hale (2001) particularly stresses the difficulties of interpreting questions in trials, while also discussing the consequences that changes in the questioning style may have (e.g. changing from an absolute question to a selective question). Informant 19, recalls a similar example:

Extract 5. [Informant 19, Chinese court interpreter]

(...) Lawyers always ask one question and then ask the same again a thousand times until you get confused, and then, of course, you become so tired that you don't even know what they've asked. They ask so many questions! 'How many shots did you hear in that moment? Were there 
a lot of people, few people or very few people? Could you describe how many people there were...?’’ They're like this, continuously pushing you.

In these situations, the questioning style is not random, but extremely pondered to achieve a certain objective. In addition to the difficulty of transferring questions and maintaining their style, court interpreters sometimes also have to deal with tiredness after interpreting for long hours, as well as messages that may be emotionally distressing (especially in cases of murder, rape or abuse), or that may confuse the interpreter and require their maximum concentration (for instance, when someone's discourse is unstructured or without obvious meaning, either intentionally or not). In this regard, while it is difficult to interpret a carefully prepared and strategic piece of discourse (as in the case of lawyers), a totally spontaneous, unstructured or contradictory narration may well become a problem from the interpreter's perspective.

Informant 18, also a court interpreter, admits adapting the message to help users understand the information, as can be seen in the following excerpt:

\section{Extract 6. [Informant 18, Latin American court interpreter]}

INF18: So you have to read the rights to the defendant. What are you doing explaining their constitutional rights to a peasant who barely knows how to write his name in Chinese? (...) And even more to a person that is in such a stressful situation, let's say, you have to tell them: ‘According to the X Law, of...' I don’t know; we would drive them even crazier, wouldn’t we? (...)

Interviewer: But then, if you have to tell them their rights, what do you do?

INF18: I kind of interpret that, I mean...

Interviewer: You adapt it to the other's education level?

INF18: Of course.

According to this excerpt, informant 18 adopts the role of the speech assistant who clarifies, filters and embellishes discourse to reach an effective communication (Hale, 2008). Considering that the interpreters' function in a trial is to 'place the person to whom they are interpreting in the same situation as a native speaker of the court's language would be' (Ortega Herráez, 2006), by adopting the role of the speech assistant and adapting the discourse, interpreters fail to serve that function, as they are placing the person to whom they are interpreting in a more advantageous situation than a native speaker of the same cultural level would be. In our sample, informant 18 seems to have a clear idea of what must be his 
role in this kind of situation, even though it deviates from what deontological codes suggest.

Sometimes, problems are based on the differences between discursive patterns. For example, some informants explain that it is difficult for Chinese users 'to get to the point' when they are asked for something. According to informants 17 and 19, Chinese users often feel the need to explain a lot of details to answer a simple question. To informant 8, a healthcare and social services interpreter, obtaining relevant information is difficult and he sometimes changes the questioning style, especially from open questions to selective questions.

This strategy could be described as a kind of modulation (Molina and Hurtado Albir 2002, p. 510), as it implies a shift in the perspective of the question. It also responds to the ‘coordinating and controlling talk’ function according to Pöllabauer (2004, p. 151), because the interpreter, aware of the provider's expectations, interrupts the user or changes the questioning style in order to get the most relevant information as soon as possible. According to Pöllabauer, this is one of the functions interpreters assume when acting as participants in the interaction and as provider's assistants. This role has also been described as that of the 'gatekeeper' (Hale, 2008) or the 'institutional gatekeeper' (Davidson, 2000). Sometimes, providers themselves implicitly or explicitly require interpreters' to adopt this role. For instance, informant 11 recalls a situation where a doctor showed her impatience (moving testily) when the patient was explaining her situation, so the interpreter just decided to pick the essential pieces of the information and summarize what the patient had just said, despite her own reluctance to summarizing information.

\section{Discussion: problems, strategies and training needs}

A better understanding of what practitioners regard as problems and difficulties may shed light on the training needs that should be covered in either formal or informal education for PSI.

First of all, word-level problems have been addressed. Most interpreters clearly detect and delimit semantic problems, and it is easier for interpreters to describe them. In fact, when asked about training needs, some interpreters also point out that they would like to expand their knowledge of the context where they work and have a better command of the vocabulary used.

Valero Garcés (2005, p. 95) stresses the importance of including terminology in training courses and to promote interpreters' awareness of the usefulness of glossaries and terminology management. This is certainly relevant and normally addressed in formal 
education, but the question is still the case for short-length ad hoc courses (20-40 hours). Moreover, it may be impossible to provide an exhaustive approach to the terminology used in all the PSI contexts and situations. Therefore, it seems that the emphasis should not be placed on memorising terms but on strategies to manage unknown terminology.

On the one hand, the reliability of certain terminological resources should be questioned. In the case of this sample, bilingual dictionaries and the Wikipedia were mentioned, two resources that present some drawbacks, as pointed out by Orozco Jutorán (2012) when talking about general translation. If terminology can be prepared in advance (before the assignment) other strategies should also be considered: reading texts related to the topic of the meeting, searching in specialised glossaries, etc.

On the other hand, managing terminology in situ also needs to be addressed. As reflected in the analysis, interpreters sometimes omit specialised terms and only describe their meaning, justifying that 'users would not understand those terms'. Interpreters adopt a paternalistic approach towards users. However, simplifying the discourse may leave users without important information about their condition (in healthcare), about their rights (in court settings) or about a specific procedure (in social services) they are entitled to know. Terminology strategies thus raise the question of role and agency, and PSI trainees should be made aware of the consequences their decisions could have. For this reason, training sessions on terminology management must still consider role issues and remain consistent with the approach provided in other subjects during the course.

Second, the strategies relied on when dealing with discourse-level problems also reflect how interpreters actively intervene in the discourse, in the construction of meaning and in the representation of the Other. Most studies based on the analysis of interpreter-mediated interactions (e.g. Davidson, 2000 or Hale, 2008, among others) reflect how interpreter intervention becomes evident in the rendition of primary participant interventions. However, this study shows how interpreters themselves acknowledge this active intervention and how they regard it as the best possible option, a fact that stresses the importance of bridging the gap between classroom practice and real life situations. Trainers should also reflect on how proto-experts (as the interpreters interviewed for this research) could benefit from recycling courses.

These findings also stress the need to relate the impartial role of the interpreter not only to ethical dilemmas, but also to the microtextual (semantics) and macrotextual (discourse) levels of the interaction. Exercises to analyse interpreted interactions (either transcribed or videotaped) and self-evaluate after role plays (audio recorded) may be useful activities for this 
purpose, always allowing for the microtextual and macrotextual dimensions of the interventions. Promoting improvised role plays (not following a specific script) may also be a good alternative to reflect the unplanned nature of the discourses trainees will find in real life.

\section{Conclusions}

The specificities of the study presented in this article must be considered when evaluating its findings: on the one hand, most interpreters had not received specific training for PSI when they were interviewed; on the other hand, their language combination (ChineseCatalan/Spanish) reflects some of the features of interpreting between distant cultures. However, some of its findings may well be translatable to other training contexts.

The examples presented in this paper corroborate the results of previous studies that place interpreter role shifts as a core issue in PSI practice (Pöchhacker, 2000; Dysart-Gale, 2005; Angelelli, 2006; Hsieh, 2006; Ortega Herráez et al., 2009, among others). While problems have been classified according to their nature, I have noted that strategies imply role shifts in both cases.

Role shifts diverge depending on the kind of problem: while the interpreter becomes an advocate for the user when word-level problems are encountered -providing more detailed or simplified explanations, as Pöchhacker (2000, p. 63) also notes when talking about 'facilitating comprehension and simplifying technical language'-, the interpreter becomes the provider's assistant or an institutional gatekeeper when pragmatic problems are detected. The hierarchical difference between the provider and the user is the main reason for these role shifts: the interpreter becomes the user's advocate in an attempt to show empathy and willingness to help the user, seeing the user as the powerless participant. However, interpreters become the providers' assistant when they feel an implicit or explicit pressure from the empowered participant, feeling that they need to save time and get information that meets the four maxims of the cooperation principle (quality, quantity, relation and manner, Grice, 1989). The interpreter intervenes in both cases to reduce the hierarchical distance between participants.

Nevertheless, solutions to both kinds of problems show a common role: that of the information gatekeeper. The interpreter decides what to say, what to omit, when to add information to better understand its context, when to interrupt the user or when to change the questioning style to get more relevant information. Interpreters' visibility (Angelelli, 2001) is evident in our sample. For this reason, while trying to focus on problems about vocabulary and terminology or about how messages are expressed, this article reflects the cross-sectional 
nature of the role and how it also affects decisions on strategies to solve different kind of problems. Therefore, curriculum design and training approaches should consider role as common content throughout the different subjects included in a broader course, and the trainers' conception of the interpreters' role should be consistent, regardless of their previous training or experience. This still remains as a challenge for training courses, especially in countries where PSI education is in its early stages and trainers come from a variety of backgrounds -conference interpreting trainers recycled in the field of PSI, PSI practitioners and sometimes also specialists in other areas, such as terminology. Reaching a consensus among trainers becomes a must to really provide a comprehensive approach to role issues.

Last but not least, the present article seeks to shed light on the topic of problems and strategies in the field of PSI. The information provided, collected by means of informal interviews, may be useful for other studies that further research the problem-strategy pairing from other methodological perspectives.

\section{Funding}

This work was supported by the Catalan Agency for Administration of University and Research Grants (AGAUR) under Grant [2014SGR545] to MIRAS research group.

\section{References}

Abuín, M. (2007). El proceso de interpretación consecutiva. Un estudio del binomio problema/estrategia [Consecutive Interpreting as a process. A study on the problemstrategy pairing]. Granada: Editorial Comares.

Angelelli, C. (2001). Deconstructing the Invisible Interpreter: a study of the interpersonal role of the interpreter in a cross-linguistic/cultural communicative event. $\mathrm{PhD}$ thesis. Stanford University.

Angelelli, C. (2006). Validating professional standards and codes. Challenges and opportunities. Interpreting, 8, 175-193. doi:10.1075/intp.8.2.04ang

Arumí, M. (2012). Problems and Strategies in Consecutive Interpreting: A Pilot Study at Two Different Stages of Interpreter Training. Meta, 57, 812-835.

Arumí Ribas, M.; Gil-Bardají, A. \& Vargas-Urpi, M. (2011). Traducció i immigració: La figura de l'intèrpret al serveis públics de Catalunya [Translation and Immigration: Public service interpreters in Catalonia]. Quaderns, 18, 199-218. Retrieved from: http://www.raco.cat/index.php/QuadernsTraduccio/article/view/245286

Davidson, B. (2000). The interpreter as institutional gatekeeper: The social-linguistic role of 
interpreters in Spanish-English medical discourse. Journal of Sociolinguistics, 4, 379-405. doi: 10.1111/1467-9481.00121

Faerch, C.; Kasper, G. (1984). Two ways of defining communication strategies. Language Learning, 34, 45-63. doi: 10.1111/j.1467-1770.1984.tb00995.x

Gil-Bardají, A. (2009). Procedures, techniques and srategies: translation process operators. Perspectives, Studies in Translatology,17, 161-173. doi: 10.1080/09076760903249372

Gile, D. (1995). Basic concepts and models for interpreter and translator training. Amsterdam \& Philadelphia: John Benjamins.

Gran, L. (1998). Developing translation/interpretation strategies and creativity. In-training development of interpreting strategies and creativity. In J. Beylard-Ozeroff, J. Králová \& B. Moser-Mercer (Eds.) Translators’ Strategies and Creativity (pp. 145-162). Amsterdam \& Philadelphia: John Benjamins.

Grice, P. (1989). Studies in the way of words. Harvard University Press.

Hale, S. (2001). How are courtroom questions interpreted? An analysis of Spanish interpreters' practices. In I. Mason (Ed.), Triadic Exchanges. Studies in Dialogue Interpreting (pp. 21-50). Manchester: St. Jerome.

Hale, S. (2007). Community Interpreting. Great Britain: Palgrave McMillan.

Hale, S. (2008). Controversies over the role of the court interpreter. In C. Valero Garcés \& A. Martin (Eds.), Crossing Borders in Community Interpreting. Definitions and dilemmas (pp. 99-122). Amsterdam; Philadelphia: John Benjamins.

Hertog, E.; Van Gucht, J. \& de Bontridder, L. (2006). Musings on Methodology. Linguistica Antverpiensa, 5, 121-132. Retrieved from: https://lans.ua.ac.be/index.php/LANSTTS/article/view/156/93

Hönig, H. \& Kussmaul, P. (1982) Strategie der Übersetzung. Ein Lehr- und Arbeitsbuch. Tübingen: Narr.

Hsieh, E. (2006). Conflicts in how interpreters manage their roles in provider-patient interactions. Social Science and Medicine, 62, 721-30.

Hurtado Albir, A. (2001). Traducción y traductología [Translation and translatology]. Madrid: Cátedra.

Kalina, S. (2000). Interpreting competences as a basis and a goal for teaching. The Interpreters' Newsletter, 10, 3-32. Retrieved from: http://hdl.handle.net/10077/2440

Kiraly, D. (1995). Pathways to translation, pedagogy and process. Kent: The Kent State University Press.

Lörscher, W. (1991). Translation performance, translation process and translation strategies: 
a psycholinguistic investigation. Tübingen: Gunter Narr Verlag.

Mayring, P. (2000). Qualitative content analysis. Forum Qualitative Sozialforschung/Forum: Qualitative Social Research, 1 (2), art. 20. Retrieved from: http://www.qualitativeresearch.net/index.php/fqs/article/view/1089/2386

Merlini, R. \& Favaron, R. (2003). Community interpreting: re-conciliation through power management. The Interpreters' Newsletter, 12, 205-229. Retrieved from: https://www.openstarts.units.it/dspace/bitstream/10077/2485/1/10.pdf

Molina, L. \& Hurtado Albir, A. (2002). Translation techniques revisited: A dynamic and functionalist approach. Meta, 47: 498-512. doi: 10.7202/008033ar

Napier, J. (2004). Interpreting omissions. A new perspective. Interpreting, 6, 117-142. doi: 10.1075/intp.6.2.02nap

Nord, C. (1991/2005). Text Analysis in Translation. Theory, Methodology, and Didactic Application of a Model for Translation-Oriented Text Analysis. (C. Nord \& P. Sparrow, Trans.). Amsterdam; Atlanta: Rodopi.

Orozco Jutorán, M. (2012). Metodología de la traducción directa del inglés al español. Materiales didácticos para traducción general y especializada [Methodology for EnglishSpanish direct translation. Didactic material for general and specialised translation]. Granada: Comares.

Ortega Herráez, J. M. (2006). Análisis de la práctica de la intepretación judicial en España. El intérprete frente a su papel profesional [Analysis of court interpreting practice in Spain. The interpreter against his professional role]. PhD thesis. Universidad de Granada.

Ortega Herráez, J. M.; Abril Martí, M. I. \& Martin, A. (2009). Community Interpreting in Spain. A comparative study of interpreters' self-perception on role in different settings. In S. Hale, U. Ozolins \& L. Stern (Eds.), The Critical Link 5. Quality in interpreting - a shared responsibility (pp. 149-167). Amsterdam; Philadelphia: John Benjamins.

Pöchhacker, F. (2000). The community interpreter's task: self-perception and provider views. In R. P. Roberts et al. (Eds.), The Critical Link 2: Interpreters in the Community (pp. 4965). Amsterdam; Philadelphia: John Benjamins.

Pöllabauer, S. (2004). Interpreting in asylum hearings. Issues of role, responsibility and power. Interpreting, 6, 143-180. doi: 10.1075/intp.6.2.03pol

Sunnari, M. (1995). Processing strategies in simultaneous interpretating: saying it all vs. synthesis. In J. Tommola (Ed.), Topics in Interpreting Research (pp. 109-119). Turku: University of Turku, Centre for Translation and Intepreting.

Valero Garcés, C. (2005). Terminology and ad hoc interpreters in public services. An 
$\begin{array}{lllll}\text { Empirical } & \text { Study. } & \text { JosTrans, } & \text { 37-96. } & \text { Retrieved }\end{array}$ from: http://www.jostrans.org/issue03/art_valero_garces.pdf

Vargas-Urpi, M. (2014). Public service interpreting for Chinese immigrants in Catalonia: a study based on intepreters', coordinators' and users' views. Language and Intercultural Communication, 4, 475-499. Doi: 10.1080/14708477.2014.934691

Vargas-Urpi, M. \& Arumí Ribas, M. (2014). Estrategias de interpretación en los servicios públicos en el ámbito educativo: estudio de caso en la combinación chino-catalán [Interpreting strategies in education public services: a case study on the Chinese-Catalan combination]. Intralinea, 16.

Retrieved from: http://www.intralinea.org/current/article/estrategias_de_interpretacion_en_los_servic ios_publicos_en_el_ambito_edu 